\title{
Erratum
}

\section{Brain Metabolic, Structural, and Behavioral Pattern Learning for Early Predictive Diagnosis of Alzheimer's Disease}

Pravat K. Mandal* and Deepika Shukla

[Journal of Alzheimer's Disease 63(3), 2018, 935-939, DOI 10.3233/JAD-180063]

https://content.iospress.com/articles/journal-of-alzheimers-disease/jad180063

A supplementary figure was missing from this article. On page 936, left column, in line 16, the reference to this figure should have been included.

Article text: Close scrutiny of metabolic patterns through advanced processing of in vivo MRS data has validated the existence of two conformers, extended $\left(\mathrm{GSH}_{\mathrm{ex}}\right)$ and closed ( $\left.\mathrm{stable}\right)\left(\mathrm{GSH}_{\mathrm{cl}}\right)$ forms of GSH in human brain, which has been first time investigated and found with its exclusiveness from well-established other metabolites such as NAA and aspartate (Figure below). 


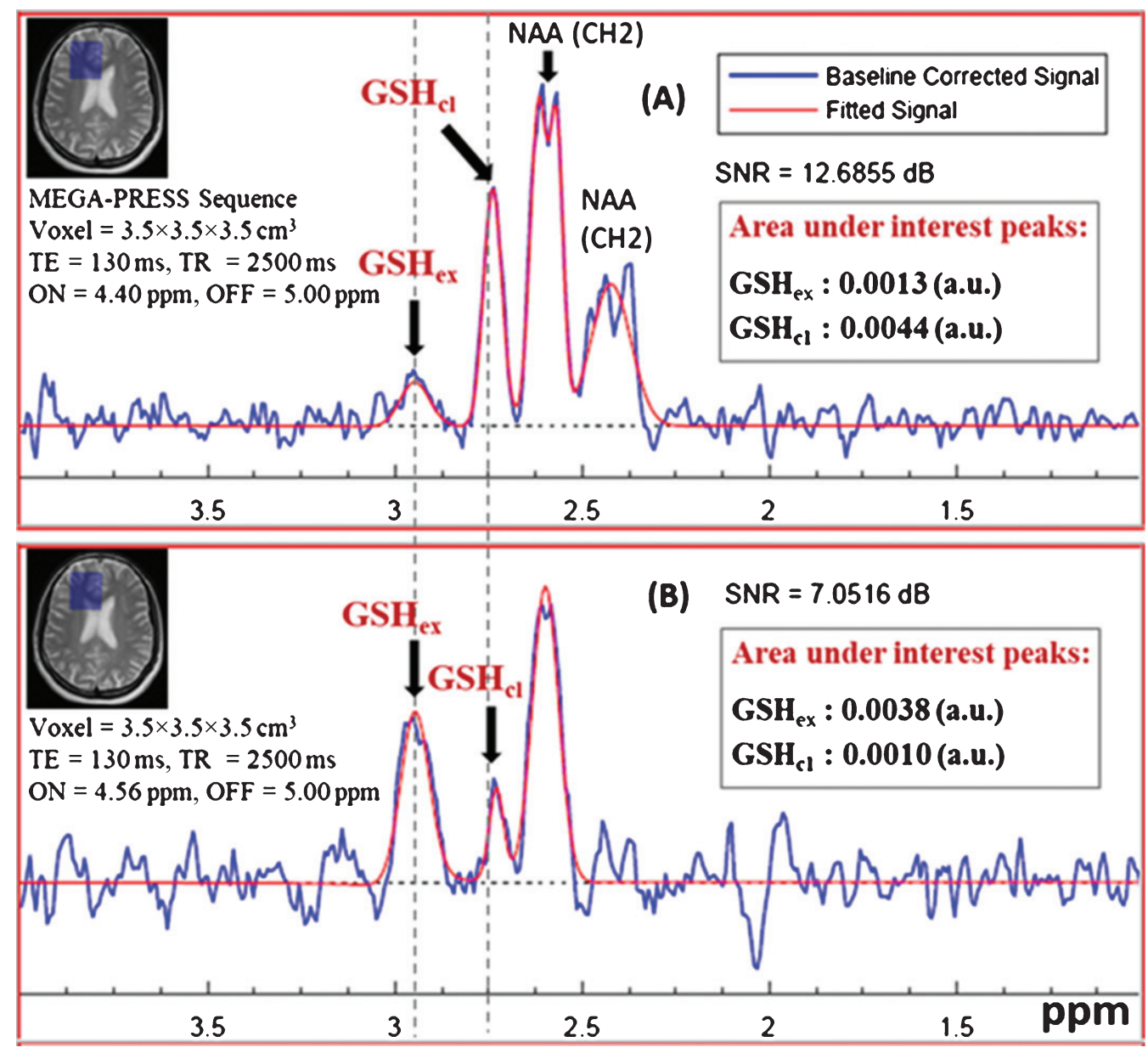

Fig. 1. Detection of the two (extended and closed) in vivo GSH conformer peaks $\left(\mathrm{GSH}_{\mathbf{e x}}\right.$ and $\left.\mathrm{GSH}_{\mathrm{cl}}\right)$ in healthy control subject using MEGA-PRESS experiment. Data was collected using 3T Philips scanner at NBRC. Data acquisition was performed with following parameters: $\mathrm{TE}=130 \mathrm{~ms}, \mathrm{TR}=2500 \mathrm{~ms},(\mathrm{~A}) \mathrm{MEGA}-\mathrm{ON} / \mathrm{OFF}=4.40 \mathrm{ppm} / 5.00 \mathrm{ppm}$ and, $(\mathrm{B}) \mathrm{MEGA}-\mathrm{ON} / \mathrm{OFF}=4.56 \mathrm{ppm} / 5.00 \mathrm{ppm})(\mathrm{voxel}$ size $=3.5 \times 3.5 \times 3.5 \mathrm{~cm}^{3}$ on right frontal cortex). 